\title{
Transition Metal Adsorbed-Doped ZnO Monolayer: 2D Dilute Magnetic Semiconductor, Magnetic Mechanism, and Beyond 2D
}

\author{
Meng Zhang, ${ }^{\dagger}$ Xinying Shi, ${ }^{\ddagger}$ Xiao Wang, ${ }^{\dagger}$ Taohai Li, ${ }^{\S}$ Marko Huttula, ${ }^{\ddagger}$ Youhua Luo, ${ }^{\dagger}$ and Wei Cao ${ }^{*},+\odot$ \\ ${ }^{\dagger}$ Department of Physics, East China University of Science and Technology, Meilong Road 130, Shanghai 200237, China \\ ${ }^{\ddagger}$ Nano and Molecular Systems Research Unit, University of Oulu, P.O. Box 3000, FIN-90014 Oulu, Finland \\ ${ }^{\S}$ College of Chemistry, Key Lab of Environment Friendly Chemistry and Application in Ministry of Education, Xiangtan University, \\ Yuhu District, Xiangtan 411105, China
}

Supporting Information

ABSTRACT: As an improvement over organic or inorganic layered crystals, the synthetic monolayer $\mathrm{ZnO}(\mathrm{M})$ inherits semiconductivity and hostability from its bulk, yet it acts as a promising host for dilute magnetic semiconductors. Here, we report the electronic and magnetic properties of $\mathrm{ZnO}(\mathrm{M})$ doped with one $3 \mathrm{~d}$ transition metal ion and simultaneously adsorbed with another $3 \mathrm{~d}$ transition metal ion. Two sequences are studied, one where the dopant is fixed to $\mathrm{Mn}$ and the adsorbate is varied from $\mathrm{Sc}$ to $\mathrm{Zn}$ and another where the dopant and adsorbate are reversed. First-principles results show that the stable adsorbed-doped systems possess a lower bandgap energy than that of the host. System magnetic moments can be tuned to $|5-x| \mu_{\mathrm{B}}$, where $x$ refers to the magnetic moment of the individual $3 \mathrm{~d}$ atom. An interplay between superexchange and direct exchange yields a ferromagnetic system dually adsorbed-doped with $\mathrm{Mn}$. In addition to a novel material design route, the magnetic interaction mechanism is found beyond two dimensions, having been identified for its three-dimensional bulk and zero-dimensional cluster counterparts.

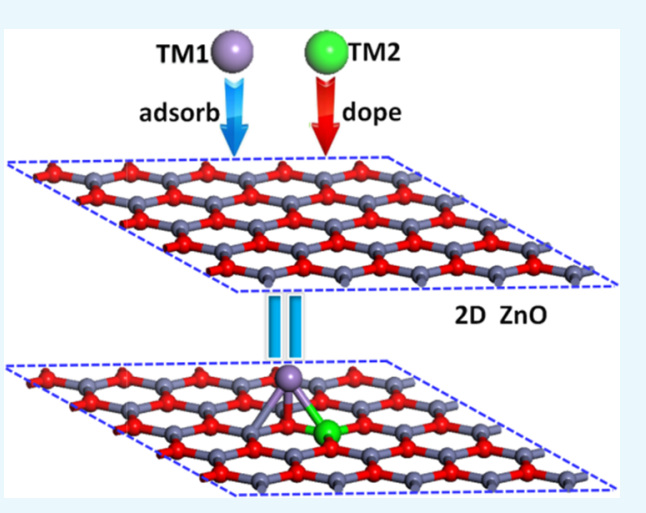

\section{INTRODUCTION}

Pioneering research on the unique properties of monolayer $\mathrm{MoS}_{2}{ }^{1-3}$ have extended studies of two-dimensional (2D) materials from organic graphene to inorganic layered crystals (ILCs). ${ }^{4}$ Benefiting from the covalent bonds in the layers and van der Waals forces among layers, these atomic crystals are easily manipulated for use in different applications. As an improvement over semimetallic graphene, ${ }^{5,6}$ most ILCs have a nonzero bandgap, yet they lack, for example, magnetic properties that would enable their wide applications in magnetic drivers or spintronics. Theoretical predictions show that magnetic properties can be realized through the introduction of noble metal nanoparticles, halogen elements, and transition metals (TMs) into the ILC systems. Consequently, dilute magnetic semiconductors (DMSs) can be formed in proper ILC hosts, for example, low-dimensional TM dichalcogenides. However, experimental realization of these routes remains challenging for naturally occurring ILCs. Foreign atoms present in the vapor deposition method undergo fast nucleation on surfaces, ${ }^{7}$ resulting in weak bonding of the dopants after they land softly on the ILC surface. ${ }^{8,9}$ Substitutional atoms within ILC systems bring into question the ability of the ILC's unique structure to survive. Covalent bonds in layers will be distorted because of differences in electronegativity between doping elements and the ILC hosts. ${ }^{10}$

As the most conventional DMS host, $\mathrm{ZnO}$ also has a stable monolayer form, $\mathrm{ZnO}(\mathrm{M})$. Honeycomb-shaped $\mathrm{ZnO}(\mathrm{M})$ is formed from its wurtzite counterpart when its thickness is decreased to a few atoms. ${ }^{11}$ Inherited from its bulk, the hostability for magnetic dopants stays with the monolayer counterpart. ${ }^{12}$ Similar to most ILCs, the layered $\mathrm{ZnO}$ structure also has the potential to be piled up to three-dimensional (3D) forms or to produce 3D heterolayer stacking, ${ }^{13}$ with each layer consisting of enough functional units, such as doped atoms. ${ }^{4}$ Analogous to doped bulk $\mathrm{ZnO},{ }^{14,15}$ 3d TM-doped $\mathrm{ZnO}(\mathrm{M})$ the $\mathrm{TM}-\mathrm{ZnO}(\mathrm{M})$ complexes-also show intrinsic magnetism. ${ }^{12}$ It is worth noting that the surface of the ILCs can be used as an adsorbent for individual atoms or clusters. Intrinsic ferromagnetism has been introduced to decorated systems of $\mathrm{TM} @ \mathrm{MoS}_{2}{ }^{16}$ and systems of TM@ZnO(M). ${ }^{17}$ It has further been noticed that doping an isoelectric cluster into an ILC will extrude atoms in the host while still keeping the layered form of the host. ${ }^{18}$ Such an arrangement between the ILC host and a cluster looks very much the same as combinations of in-plane substitution ${ }^{12}$ and out-of-plane adsorption. ${ }^{17}$ Thus, a strategy that combines doping and adsorption in a $\mathrm{ZnO}(\mathrm{M})$ system may yield very special magnetic properties from the ILCs and correlation schemes beyond DMS manipulations.

Here, we report a first-principles investigation of the electronic and magnetic properties of monolayer $\mathrm{ZnO}$

Received: January 25, 2017

Accepted: March 15, 2017

Published: March 29, 2017 
simultaneously doped and adsorbed with $3 \mathrm{~d}$ TM dopants. As shown in Figure 1, the first TM impurity (TM1) acts as the

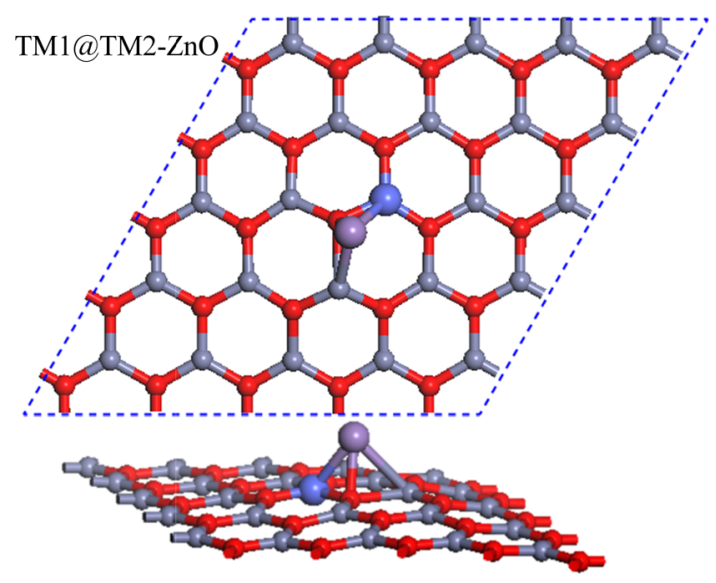

Figure 1. Optimized geometric structures of a TM1 atom adsorbed onto monolayer $\mathrm{ZnO}$ doped by a TM2 atom viewed from the top (top) and side (bottom). The gray, red, purple, and blue spheres represent $\mathrm{Zn}, \mathrm{O}, \mathrm{TM} 1$, and TM2 atoms, respectively.

adsorbate, whereas the second (TM2) acts as the dopant in a 5 $\times 5 \mathrm{ZnO}(\mathrm{M})$ supercell. This system is named TM1@TM2$\mathrm{ZnO}$. Because of the large number of possible combinations of 3d TM1 and TM2 varieties, we constructed systems by first fixing TM1 to $\mathrm{Mn}(Z=26)$ and varying TM2 from $\mathrm{Sc}$ to $\mathrm{Zn}(Z$ = 21-30), considering the robust ferromagnetism of $\mathrm{Mn}$ doped $^{12}$ and decorated $\mathrm{ZnO}$ systems. ${ }^{17}$ The doping route was further extended via alternating the positions of the dopants and adsorbates, for example, doping $\mathrm{Mn}$ in the monolayer plane and adsorbing $\mathrm{Sc}$ to $\mathrm{Cu}$ on the plane. In total, 20 adsorbed-doped systems were studied.

\section{RESULTS AND DISCUSSION}

After a full optimization of all possible adsorbing positions including magnetic order effects, it is found that the most stable adsorption site in both the Mn@TM2-ZnO and TM1@Mn$\mathrm{ZnO}$ systems is above the $\mathrm{O}$ atom linked to the doped TM2 atom, except for $\mathrm{Zn} @ \mathrm{Mn}-\mathrm{ZnO}$, as Figure 1 shows. Other possible adsorption sites at the bridge, hollow face, and top $\mathrm{Zn}$ atom as well as above other $\mathrm{O}$ atoms apart from the TM2 atom are energetically unfavorable. Figure $S 1$ shows zoomed-in images of the adsorbed positions and structures along with bond lengths $d$ (in angstroms). Monolayer $\mathrm{ZnO}(\mathrm{M})$ is badly distorted in $\mathrm{Mn} @ \mathrm{Ni}-\mathrm{ZnO}$ and $\mathrm{Mn} @ \mathrm{Cu}-\mathrm{ZnO}$ with a back row of doping TM2 elements and in Sc@Mn-ZnO, Ti@Mn$\mathrm{ZnO}$, and $\mathrm{V} @ \mathrm{Mn}-\mathrm{ZnO}$ with a front row of adsorbing TM1 elements.

The thermodynamic stability of TM1@TM2-ZnO was analyzed by calculating the adsorption energies $E_{\mathrm{ad}}$, defined as

$$
\begin{gathered}
E_{\mathrm{ad}}=\left[E_{\text {total }}(\mathrm{TM} 2-\mathrm{ZnO})+E(\mathrm{TM} 1)\right] \\
-E_{\text {total }}(\mathrm{TM} 1 @ \mathrm{TM} 2-\mathrm{ZnO})
\end{gathered}
$$

where $E_{\text {total }}(\mathrm{TM} 1 @ \mathrm{TM} 2-\mathrm{ZnO})$ and $E_{\text {total }}(\mathrm{TM} 2-\mathrm{ZnO})$ represent total energies of the lowest energy structures of TM1@ $\mathrm{TM} 2-\mathrm{ZnO}$ and $\mathrm{TM} 2-\mathrm{ZnO}$, respectively, and $E(\mathrm{TM} 1)$ is the energy of the individual TM1 atom. All adsorption energies are found to be largely above zero, as shown in Table 1, indicating an energetically favorable process for the adsorption of TM1 atoms in the doped $\mathrm{ZnO}$ layer. $\mathrm{Mn} @ \mathrm{Cr}-\mathrm{ZnO}$ and $\mathrm{Cr} @ \mathrm{Mn}-$
Table 1. Adsorbed Position of the TM1 Atom, Bond Lengths $d$ (in Angstroms) of the TM1 Atom and Host TM2- $\mathrm{ZnO}$, Adsorption Energies $E_{\mathrm{ad}}$ (in $\mathrm{eV}$ ), and Bandgap (in $\mathrm{eV}$ ) of TM1@TM2-ZnO Systems for the Lowest Energy Structures $^{a}$

$\begin{array}{ccccc}\text { system TM1@TM2-ZnO } & \text { adsorbed position } & d & E_{\text {ad }} & \text { bandgap } \\ \mathrm{Mn} @ \mathrm{Sc}-\mathrm{ZnO} & \text { O top } & 2.147 & 1.11 & 0.05 \\ \mathrm{Mn} @ \mathrm{Ti}-\mathrm{ZnO} & \text { O top } & 3.025 & 1.52 & 0.38 \\ \mathrm{Mn} @ \mathrm{~V}-\mathrm{ZnO} & \text { O top } & 2.961 & 1.63 & 0.46 \\ \mathrm{Mn} @ \mathrm{Cr}-\mathrm{ZnO} & \text { O top } & 2.006 & 1.75 & 0.73 \\ \mathrm{Mn} @ \mathrm{Mn}-\mathrm{ZnO} & \text { O top } & 2.002 & 1.30 & 0.81 \\ \mathrm{Mn} @ \mathrm{Fe}-\mathrm{ZnO} & \text { O top } & 1.951 & 1.28 & 0.75 \\ \mathrm{Mn} @ \mathrm{Co}-\mathrm{ZnO} & \text { O top } & 2.008 & 0.94 & 0.68 \\ \mathrm{Mn} @ \mathrm{Ni}-\mathrm{ZnO} & - & - & - & - \\ \mathrm{Mn} @ \mathrm{Cu}-\mathrm{ZnO} & - & - & - & - \\ \mathrm{Mn} @ \mathrm{Zn}-\mathrm{ZnO} & \text { O top } & 1.999 & 0.39 & 0.79 \\ \mathrm{Sc} @ \mathrm{Mn}-\mathrm{ZnO} & - & - & - & - \\ \mathrm{Ti} @ \mathrm{Mn}-\mathrm{ZnO} & - & - & - & - \\ \mathrm{V} @ \mathrm{Mn}-\mathrm{ZnO} & - & - & - & - \\ \mathrm{Cr} @ \mathrm{Mn}-\mathrm{ZnO} & \text { O top } & 1.873 & 1.61 & 0.52 \\ \mathrm{Mn} @ \mathrm{Mn}-\mathrm{ZnO} & \text { O top } & 2.002 & 1.30 & 0.81 \\ \mathrm{Fe} @ \mathrm{Mn}-\mathrm{ZnO} & \text { O top } & 1.963 & 0.82 & 0.05 \\ \mathrm{Co} @ \mathrm{Mn}-\mathrm{ZnO} & \text { O top } & 1.951 & 1.38 & 0.76 \\ \mathrm{Ni} @ \mathrm{Mn}-\mathrm{ZnO} & \text { O top } & 1.990 & 1.25 & 0.24 \\ \mathrm{Cu} @ \mathrm{Mn}-\mathrm{ZnO} & \text { O top } & 2.004 & 1.07 & 0.49 \\ \mathrm{Zn} @ \mathrm{Mn}-\mathrm{ZnO} & \text { Mn top } & 2.767 & 0.25 & 0.71\end{array}$

${ }^{a}$ Dashes (-) refer to $\mathrm{ZnO}$ monolayer structures that cannot be maintained.

$\mathrm{ZnO}$ have the largest $E_{\mathrm{ad}}$ in their respective groups, which suggests that $\mathrm{Cr}$ and $\mathrm{Mn}$ atoms could stabilize monolayer $\mathrm{ZnO}$ by doping and adsorption. Obviously, there is a strong interaction between the adsorbed TM1 atoms and the host $\mathrm{O}$ atom. The TM1-O bond has ionic character. For example, charge transfer from $\mathrm{Mn}$ to $\mathrm{O}$ in $\mathrm{Mn} @ \mathrm{Cr}-\mathrm{ZnO}$ and that from $\mathrm{Cr}$ to $\mathrm{O}$ in $\mathrm{Cr} @ \mathrm{Mn}-\mathrm{ZnO}$ is $0.153 e$ and $0.249 e$, respectively, according to Mulliken population analysis.

The dynamic stabilities of the TM1@TM2- $\mathrm{ZnO}$ systems at room temperature $(T=300 \mathrm{~K})$ were also examined using molecular dynamics simulations implemented in the $\mathrm{DMOL}^{3}$ code. The Nosé-Hoover thermostat was used for NVT dynamics. The simulated results for $\mathrm{Mn} @ \mathrm{Cr}-\mathrm{ZnO}$ and $\mathrm{Cr} @$ $\mathrm{Mn}-\mathrm{ZnO}$ are shown in Figure S2. The integrity of the structures is still maintained after the systems are heated for 10 ps. No domino effect appears, and the total potential energies remain almost invariant. Thus, the adsorbed-doped systems are stable at room temperature.

Electronic structures of the TM1@TM2-ZnO systems are compared with those of the pristine $\mathrm{ZnO}$ monolayer. From our calculations, $\mathrm{ZnO}(\mathrm{M})$ is a direct bandgap semiconductor with an energy of $E_{\text {gap }}=1.90 \mathrm{eV}$ at the $\Gamma$ point. This value is slightly larger than that obtained in previous density functional theory (DFT) studies, approximately $1.70 \mathrm{eV},{ }^{19-21}$ which is most probably due to the use of the double numerical plus polarization (DNP) basis set in the present study. Compared with that of the host, bandgap values are all reduced in the TM1@TM2-ZnO systems. Such a reduction can significantly affect the optical and transport properties of the material. It can be seen from Table 1 that $\mathrm{Mn} @ \mathrm{Mn}-\mathrm{ZnO}$ has the largest bandgap among TM1@TM2-ZnO at $0.81 \mathrm{eV}$. It should be noted that $\mathrm{Mn} @ \mathrm{Sc}-\mathrm{ZnO}$ and $\mathrm{Fe} @ \mathrm{Mn}-\mathrm{ZnO}$ have the smallest bandgap, $0.05 \mathrm{eV}$, which is very close to that of semimetals. The 
bandgap of $\mathrm{Mn} @ \mathrm{TM} 2-\mathrm{ZnO}$ gradually decreases from $\mathrm{Mn}$ substitution on both sides toward $\mathrm{Sc}$ and $\mathrm{Cu}$. On the other hand, the bandgap of TM1@Mn-ZnO exhibits odd-even alternations with the exception of $\mathrm{Zn} @ \mathrm{Mn}-\mathrm{ZnO}$. The host $\mathrm{Zn}$ atom has completely filled $\mathrm{d}$ and s shells. However, Sc, Ti, V, $\mathrm{Cr}, \mathrm{Mn}, \mathrm{Fe}, \mathrm{Co}$, and $\mathrm{Ni}$ all have open d shells. By taking into consideration the structural difference shown in Figure S1, we can conclude that a partially filled d shell of TM atoms plays a crucial role in determining the structures and properties of the TM1@TM2-ZnO systems. Figure S3 shows that doping and adsorption by TM atoms introduce electrons into both the conduction and valence bands of the $\mathrm{ZnO}$ monolayer sheet, which should significantly enhance the electric conductivity and chemical activity of the $\mathrm{ZnO}(\mathrm{M})$ sheet. The conduction band minimum (CBM) above the Fermi level of TM1@TM2-ZnO mainly consisted of bands arising from pure $\mathrm{ZnO}$. The TM atoms significantly reduce the $\mathrm{CBM}$ from that of $\mathrm{ZnO}$. On the other hand, bands next to the valence band maximum of TM1@TM2-ZnO are mainly composed of bands from the TM atoms.

The magnetic properties in the present adsorbed-doped systems are very different from those of solely doped or decorated monolayers. In the TM-ZnO or TM@ZnO layers, the magnetic moments of impure TM atoms are not quenched by the nonmagnetic host, $\mathrm{ZnO}(\mathrm{M})$. For example, the adsorbed $\mathrm{TM}$ atoms are able to maintain their atomic spin magnetic moments in TM@ZnO systems, as shown in Table S1. This result agrees well with the results of other available DFT studies. $^{17,22,23}$ The total magnetic moments of the TM1@ TM2-ZnO complex and the local magnetic moments of the adsorbed TM1 atom and doped TM2 atom are tabulated in Table 2. Both Mn@TM2-ZnO and TM1@Mn-ZnO generate tunable magnetic moments, varying from 0 to $5 \mu_{\mathrm{B}}$ per cell with the different TM atoms. In both cases, the TM atoms counter the magnetic character of the $\mathrm{Mn}$ atoms. The $\mathrm{Mn}$ atoms are the major contributors to the total magnetic moment, whereas the TM atoms hold only a minor magnetic moment. A single Mn atom has five unpaired electrons with $5 \mu_{\mathrm{B}}$ magnetic moments, so the total magnetic moment of the TM1@TM2-ZnO complex can be viewed as $|5-x| \mu_{\mathrm{B}}$, where $x$ is the magnetic moment of another TM atom. Within this trend, the ground spin state of $\mathrm{Mn} @ \mathrm{Mn}-\mathrm{ZnO}$ has zero magnetic moment, as shown in Table 2. Other spin states are less stable than the one with zero magnetic moment (see Figure S4). The above result indicates that monolayer $\mathrm{ZnO}$ can be easily switched between magnetic and nonmagnetic via adsorbing or dissociating a $\mathrm{Mn}$ atom.

Because all stable complexes contain two TM atoms bending toward each other, we also compare the magnetism of the doped-adsorbed systems with that of individual TM-Mn dimers. The magnetic properties in the present $2 \mathrm{D}$ systems are completely different from those of TM-Mn OD clusters. As shown in Table S2, the magnetic moments of TM-Mn clusters demonstrate a regular pattern of $(5+y) \mu_{\mathrm{B}}$, where $y$ represents the magnetic moment of the individual TM atom from $\mathrm{Cr}$ to $\mathrm{Zn}$. However, this formulation does not apply to TM-Mn, where the $3 \mathrm{~d}$ orbital of TM is less than half-filled. The $\mathrm{s}$ electrons from these TMs also contribute to the magnetism of the dimer. The first three dimers $(\mathrm{TM}=\mathrm{Sc}, \mathrm{Ti}$, and $\mathrm{V})$ possess magnetic moments of $(5-x-2) \mu_{\mathrm{B}}$, where $-2 \mu_{\mathrm{B}}$ arises from excitations of two s electrons to $\mathrm{d}$ orbitals, partially canceling the electron spin majority. Such an electron configuration also explains structural deteriorations in the corresponding TM@
Table 2. Local Magnetic Moments $\left(\mu_{\mathrm{B}}\right)$ on Adsorbed TM1 and Doped TM2 Atoms and Total Magnetic Moment of the TM1@TM2-ZnO Systems for the Lowest Energy Structures $^{a}$

\begin{tabular}{cccc} 
& \multicolumn{3}{c}{ moment $\left(\mu_{\mathrm{B}}\right)$} \\
\cline { 2 - 4 } system TM1@TM2-ZnO & adsorbed Mn & doped TM & total \\
$\mathrm{Mn} @ \mathrm{Sc}-\mathrm{ZnO}$ & 4.847 & -0.295 & 4 \\
$\mathrm{Mn} @ \mathrm{Ti}-\mathrm{ZnO}$ & 4.108 & -0.607 & 3 \\
$\mathrm{Mn} @ \mathrm{~V}-\mathrm{ZnO}$ & 3.956 & -1.589 & 2 \\
$\mathrm{Mn} @ \mathrm{Cr}-\mathrm{ZnO}$ & 4.715 & -3.453 & 1 \\
$\mathrm{Mn} @ \mathrm{Mn}-\mathrm{ZnO}$ & 4.873 & -4.516 & 0 \\
$\mathrm{Mn} @ \mathrm{Fe}-\mathrm{ZnO}$ & 4.985 & -3.528 & 1 \\
$\mathrm{Mn} @ \mathrm{Co}-\mathrm{ZnO}$ & 4.902 & -2.509 & 2 \\
$\mathrm{Mn} @ \mathrm{Ni}-\mathrm{ZnO}$ & - & - & - \\
$\mathrm{Mn} @ \mathrm{Cu}-\mathrm{ZnO}$ & - & - & - \\
$\mathrm{Mn} @ \mathrm{Zn}-\mathrm{ZnO}$ & 5.08 & -0.008 & 5 \\
system TM1@TM2-ZnO & doped Mn & adsorbed TM & total \\
$\mathrm{Sc} @ \mathrm{Mn}-\mathrm{ZnO}$ & - & - & - \\
$\mathrm{Ti} @ \mathrm{Mn}-\mathrm{ZnO}$ & - & - & - \\
$\mathrm{V} @ \mathrm{Mn}-\mathrm{ZnO}$ & - & - & - \\
$\mathrm{Cr} @ \mathrm{Mn}-\mathrm{ZnO}$ & 4.614 & -4.132 & 1 \\
$\mathrm{Mn} @ \mathrm{Mn}-\mathrm{ZnO}$ & 4.516 & -4.873 & 0 \\
$\mathrm{Fe} @ \mathrm{Mn}-\mathrm{ZnO}$ & 3.746 & -2.809 & 1 \\
$\mathrm{Co} @ \mathrm{Mn}-\mathrm{ZnO}$ & 4.491 & -2.607 & 2 \\
$\mathrm{Ni} @ \mathrm{Mn}-\mathrm{ZnO}$ & 4.193 & -1.374 & 3 \\
$\mathrm{Cu} @ \mathrm{Mn}-\mathrm{ZnO}$ & 4.569 & -0.594 & 4 \\
$\mathrm{Zn} @ \mathrm{Mn}-\mathrm{ZnO}$ & 4.638 & 0.104 & 5
\end{tabular}

${ }^{a}$ Dashes (-) refer to the $\mathrm{ZnO}$ monolayer structure that cannot be maintained.

$\mathrm{Mn}-\mathrm{ZnO}(\mathrm{TM}=\mathrm{Sc}, \mathrm{Ti}$, and $\mathrm{V})$ monolayers: both 4 s electrons of the adsorbed TM atom preferably occupy $d$ states in the nearby "dimer" because of magnetic interactions, leaving the $\mathrm{s}$ shell empty. Consequently, electrons from neighboring atoms tend to occupy the vacancies, drag the atoms out of plane, and distort the 2D structure of the host (see Figure S5).

Extensive comparisons are performed for electronic structures and magnetisms between the present doped-adsorbed systems and the TM-doped nitride semiconductors. In general, the bandgaps of both $\mathrm{ZnO}(\mathrm{M})$ and the nitrides were reduced after introducing the TM dopants into the semiconductive hosts. ${ }^{24,25}$ However, differing from the half-metallic or even Dirac half-metallic properties ${ }^{26}$ resulting from the doped nitrides, the present systems still keep their semiconductive nature with nonzero bandgaps. Additional bands that arise from the dopants do not cross the Fermi level in the systems investigated here. The magnetic properties of the $\mathrm{ZnO}(\mathrm{M})$ systems are also different from the nitrides after being modulated by two external dopants. Although the magnetism can be switched gradually here, ferromagnetism dominates the aforementioned doped nitride compounds. In an extreme case with a cluster of reduced space, for example, $\mathrm{Cr}_{2}$-doped $(\mathrm{GaN})_{x}$, the magnetism from the dimer, although it can be affected partially by the host, still contributes to the final ferromagnetism of the doped systems. ${ }^{27,28}$

Despite successes in the design of DMSs, the magnetic properties of the present systems, especially antiferromagnetic $\mathrm{Mn} @ \mathrm{Mn}-\mathrm{ZnO}$, raise interesting questions about their origins. To qualitatively rationalize the magnetic properties, the orbitals of the highest occupied valence band (HOVB) of Mn@Mn$\mathrm{ZnO}$ are visualized in Figure 2. In Figure 2, HOVB-1 indicates that the $2 \mathrm{p}$ orbital of the $\mathrm{O}$ atom overlaps with the $3 \mathrm{~d}$ orbital of 


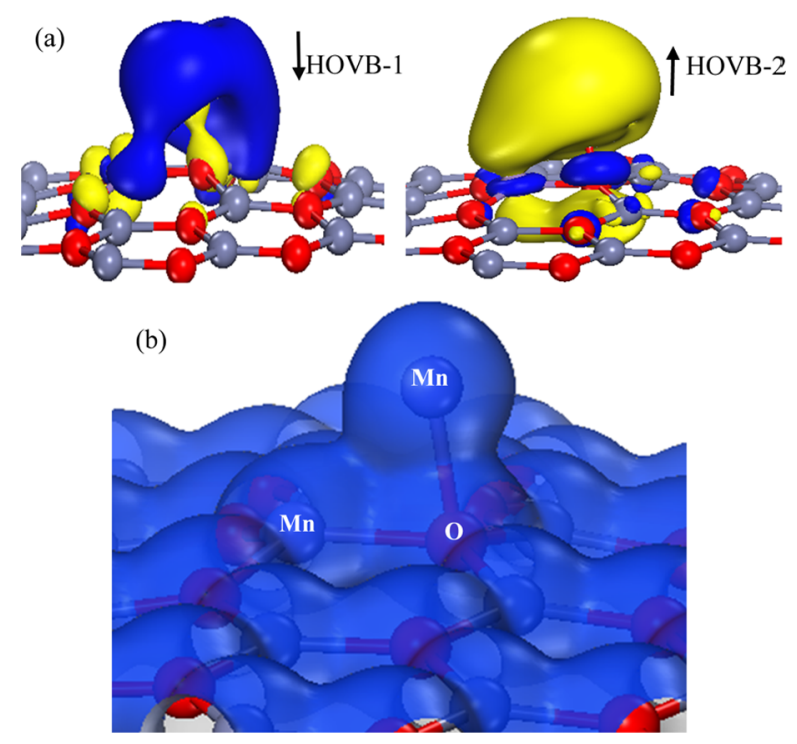

Figure 2. Orbitals of the HOVB (a) and total electronic charge density near the Mn atoms (b) of $\mathrm{Mn} @ \mathrm{Mn}-\mathrm{ZnO}$. Upward and downward arrows indicate spin-up and spin-down, respectively. The surface isovalues for orbitals and electron density are 0.03 and $0.23 \mathrm{e} / \AA^{3}$, respectively.

the $\mathrm{Mn}$ atom on top (adsorbed), whereas HOVB-2 presents the effective orbital overlap between the $2 p$ orbital of the $\mathrm{O}$ atom and the $3 \mathrm{~d}$ orbital of the $\mathrm{Mn}$ atom (doped). The $\mathrm{Mn}-$ $\mathrm{O}-\mathrm{Mn}$ bond angle is approximately $90^{\circ}$, close to the value of $90^{\circ}$ for a face-centered cubic $\mathrm{MnO}$ crystal. Spin coupling between $\mathrm{Mn}$ cations is mainly performed through the bonded oxygen atom in between. Thus, superexchange coupling between $\mathrm{Mn}$ cations in close proximity occurs through the $\mathrm{O}$ anion, resulting in an antiferromagnetic interaction of the spins in these two neighboring $\mathrm{Mn}$ atoms. This phenomenon is different from the ferromagnetic coupling in a Co-doped $\mathrm{ZnO}(\mathrm{M})$ sheet, which is mainly guided by a direct exchange interaction without any additional defect as reported by Schmidt et al. ${ }^{29}$ However, such a local superexchange interaction is also different from the bulk phase of $\mathrm{MnO}$, where the electron coupling in the entire crystal happens completely through oxygen. ${ }^{30,31}$ In Figure $2 \mathrm{~b}$, significant interactions can also be found among the neighboring $\mathrm{Mn}$, $\mathrm{O}$, and $\mathrm{Mn}$ atoms. Direct electron density overlap between two $\mathrm{Mn}$ atoms is identified, similar to the direct exchange between $\mathrm{Mn}$ atoms in a Mn dimer, ${ }^{16}$ but it produces broken symmetry. Thus, the antiferromagnetism resulted from the interplay between the local $\mathrm{Mn}-\mathrm{O}-\mathrm{Mn}$ superexchange effect and direct magnetic exchange between two Mn impurities. To examine this, we take the electronic partial density of states (PDOS) plots of $\mathrm{Mn}-\mathrm{O}-\mathrm{Mn}$ atoms in Figure 3 to show hybridization in the studied monolayer. The superposition of one sharp peak originates from the $\mathrm{d}$ orbital of adsorbed $\mathrm{Mn}$ and the $\mathrm{p}$ orbital of $\mathrm{O}$ at $-1.5 \mathrm{eV}$ near the Fermi level. On the other hand, there is another obvious peak superposition between the $d$ orbital of doped $\mathrm{Mn}$ and the $\mathrm{p}$ orbital of $\mathrm{O}$ in the $-6 \mathrm{eV}$ region. Again, the PDOS in the present systems serves different roles toward the magnetic properties compared with that for the doped nitrides, where the majority of the density of states accounts for their metallicity and the minority accounts for their semiconductivity. ${ }^{32}$

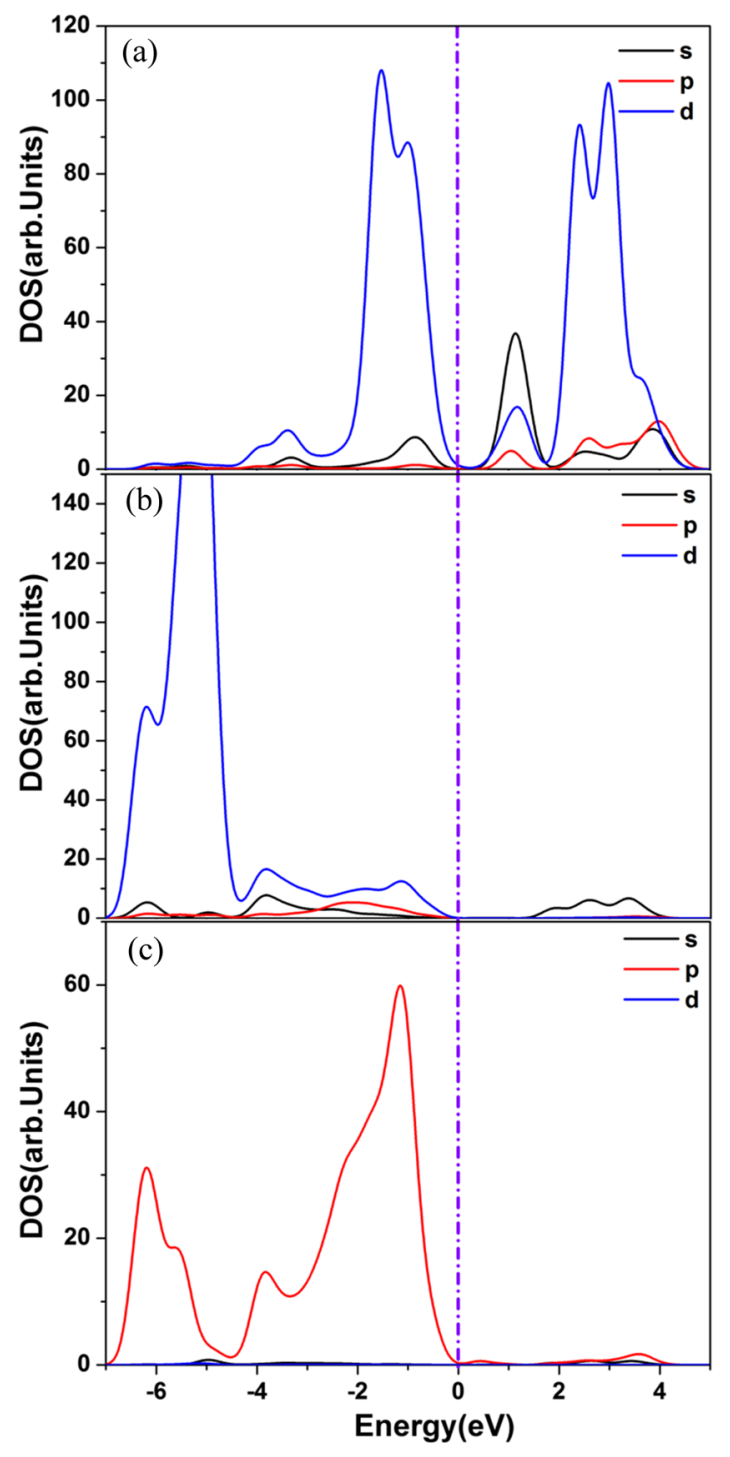

Figure 3. PDOS of the $\mathrm{Mn} @ \mathrm{Mn}-\mathrm{ZnO}$ complex: (a) adsorbed $\mathrm{Mn}$ atom, (b) doped $\mathrm{Mn}$ atom, and (c) $\mathrm{O}$ atom participating in contraction with the $\mathrm{Mn}$ atom. The vertical dashed-dotted lines indicate the Fermi level.

\section{CONCLUSIONS}

In conclusion, we presented a successful strategy to tailor the electronic and magnetic properties of a $\mathrm{ZnO}$ monolayer via doping and sequentially adsorbing TM atoms. Considering the technical readiness of $\mathrm{ZnO}$ manipulation, ${ }^{15}$ experimental applications of the designed systems are highly feasible. In addition to yielding unique intrinsic DMSs, the first-principles results also give new insights into magnetic coupling within adsorbed-doped systems. An interplay between local superexchange and direct magnetic exchange is found in the Mn@ $\mathrm{Mn}-\mathrm{ZnO}$ system. It is hoped that the present work will inspire fundamental research on magnetic coupling mechanisms in low dimensions in addition to facilitating advances in material functionality.

\section{COMPUTATIONAL METHODS}

All calculations were performed using the $\mathrm{DMOL}^{3}$ package. ${ }^{33} \mathrm{~A}$ relativistic semicore pseudopotential replacing core electrons by a single effective potential was used for the spin-unrestricted 
calculations. The DNP functions were employed as basis. Generalized gradient approximation in the Perdew-BurkeErnzerhof functional form was chosen. ${ }^{34}$ During geometry optimization, the quality of the self-consistent field convergence tolerance was set as "fine". A convergence criterion of $1 \times 10^{-6}$ hartree was applied on the total energy and electron density, 2 $\times 10^{-3}$ hartree $/ \AA$ on the gradient, and $5 \times 10^{-3} \AA$ on lattice displacements. The $5 \times 5$ supercells were constructed from 51 atoms comprising $24 \mathrm{Zn}$ atoms, $25 \mathrm{O}$ atoms, 1 adsorbing TM1 atom, and 1 doping TM2 atom for the monolayer TM1@ TM2-ZnO system. A vacuum region of $20 \AA$ was selected in the $z$-direction to exclude mirror interactions between neighboring images. To elucidate the magnetic properties of the system, we carried out a detailed calculation for each possible spin multiplicity ranging from 1 to 12 to determine the ground spin state.

The strategy was carried out via optimizing the $\mathrm{ZnO}(\mathrm{M})$ host, which was followed by doping and finalized by adsorbing adsorbates on the doped monolayer. A $5 \times 5$ supercell of $\mathrm{ZnO}(\mathrm{M})$ matrix was first investigated, and the results are crosschecked with those reported in the literature. The supercell was relaxed before doping and adsorbing the TM atoms. The lattice constant of pristine monolayer $\mathrm{ZnO}$ is $3.298 \AA$, with a $\mathrm{Zn}-\mathrm{O}$ bond length of $\sim 1.91 \AA$, agreeing well with the experimental value of $1.92 \AA^{11}$ and other DFT calculations of $1.90 \AA^{19-21}$ Then, the TM2 doped into $\mathrm{ZnO}(\mathrm{M})$ with $\mathrm{Zn}$ site substitution (TM2-ZnO) was optimized. Finally, another TM1 atom adsorbed on the surface of the TM2- $\mathrm{ZnO}$ was constructed and named TM1@TM2-ZnO.

\section{ASSOCIATED CONTENT}

\section{S Supporting Information}

The Supporting Information is available free of charge on the ACS Publications website at DOI: 10.1021/acsomega.7b00093.

Properties of the TM@ZnO system, magnetic moment of TM-Mn clusters, structures of TM1@TM2-ZnO systems, molecular dynamics simulation of $\mathrm{Mn} @ \mathrm{Cr}-$ $\mathrm{ZnO}$ and $\mathrm{Cr} @ \mathrm{Mn}-\mathrm{ZnO}$, band structures of TM1@ TM2- $\mathrm{ZnO}$, relative energies of different spin states of the $\mathrm{Mn} @ \mathrm{Mn}-\mathrm{ZnO}$ system, and geometric structures of $\mathrm{X} @ \mathrm{Mn}-\mathrm{ZnO}(\mathrm{X}=\mathrm{Sc}, \mathrm{Ti}$, and V) (PDF)

\section{AUTHOR INFORMATION}

\section{Corresponding Author}

*E-mail: wei.cao@oulu.fi (W.C.).

\section{ORCID $\odot$}

Meng Zhang: 0000-0002-9618-075X

Xinying Shi: 0000-0002-0649-8992

Wei Cao: 0000-0003-3139-1780

\section{Author Contributions}

The project was initiated by W.C. and conceived by W.C. and M.Z. M.Z. conducted the calculations. X.S., M.H., X.W., T.L., and Y.L. participated in the calculations and structural optimization. The article was written by M.Z. and W.C. All authors have read and commented on the manuscript.

\section{Notes}

The authors declare no competing financial interest.

\section{ACKNOWLEDGMENTS}

The authors acknowledge with great thanks Prof. Jian-Zu Zhang for his insightful suggestions and discussions. This work is financially supported by the National Natural Science Foundation of China (grant nos. 21303054, 21601149), the Strategic Grant of Oulu University, and the European Union Regional Development Foundation and Council of Oulu Region. X.S. acknowledges financial support from China Scholarship Council.

\section{REFERENCES}

(1) Splendiani, A.; Sun, L.; Zhang, Y.; Li, T.; Kim, J.; Chim, C.-Y.; Galli, G.; Wang, F. Emerging photoluminescence in monolayer $\mathrm{MoS}_{2}$. Nano Lett. 2010, 10, 1271-1275.

(2) Mak, K. F.; Lee, C.; Hone, J.; Shan, J.; Heinz, T. F. Atomically thin $\mathrm{MoS}_{2}$ : A new direct-gap semiconductor. Phys. Rev. Lett. 2010, 105, 136805.

(3) Radisavljevic, B.; Radenovic, A.; Brivio, J.; Giacometti, V.; Kis, A. Single-layer $\mathrm{MoS}_{2}$ transistors. Nat. Nanotechnol. 2011, 6, 147-150.

(4) Geim, A. K.; Grigorieva, I. V. van der Waals heterostructures. Nature 2013, 499, 419-425.

(5) Novoselov, K. S.; Geim, A. K.; Morozov, S. V.; Jiang, D.; Zhang, Y.; Dubonos, S. V.; Grigorieva, I. V.; Firsov, A. A. Electric field effect in atomically thin carbon films. Science 2004, 306, 666-669.

(6) Novoselov, K. S.; Geim, A. K.; Morozov, S. V.; Jiang, D.; Katsnelson, M. I.; Grigorieva, I. V.; Dubonos, S. V.; Firsov, A. A. Twodimensional gas of massless Dirac fermions in graphene. Nature 2005, 438, 197-200.

(7) Gong, C.; Huang, C.; Miller, J.; Cheng, L.; Hao, Y.; Cobden, D.; Kim, J.; Ruoff, R. S.; Wallace, R. M.; Cho, K.; Xu, X.; Chabal, Y. J. Metal contacts on physical vapor deposited monolayer $\mathrm{MoS}_{2}$. ACS Nano 2013, 7, 11350-11357.

(8) Popok, V. N.; Barke, I.; Campbell, E. E. B.; Meiwes-Broer, K.-H. Cluster-surface interaction: From soft landing to implantation. Surf. Sci. Rep. 2011, 66, 347-377.

(9) Fan, J. A.; Wu, C.; Bao, K.; Bao, J.; Bardhan, R.; Halas, N. J.; Manoharan, V. N.; Nordlander, P.; Shvets, G.; Capasso, F. SelfAssembled Plasmonic Nanoparticle Clusters. Science 2010, 328, 11351138.

(10) Ataca, C.; Şahin, H.; Ciraci, S. Stable, single-layer $\mathrm{MX}_{2}$ transition-metal oxides and dichalcogenides in a honeycomb-like structure. J. Phys. Chem. C 2012, 116, 8983-8999.

(11) Tusche, C.; Meyerheim, H. L.; Kirschner, J. Observation of depolarized $\mathrm{ZnO}(0001)$ monolayers: Formation of unreconstructed planar sheets. Phys. Rev. Lett. 2007, 99, 026102.

(12) Ren, J.; Zhang, H.; Cheng, X. Electronic and magnetic properties of all $3 \mathrm{~d}$ transition-metal-doped $\mathrm{ZnO}$ monolayers. Int. J. Quantum Chem. 2013, 113, 2243-2250.

(13) Li, X.; Lin, M.-W.; Lin, J.; Huang, B.; Puretzky, A. A.; Ma, C.; Wang, K.; Zhou, W.; Pantelides, S. T.; Chi, M.; Kravchenko, I.; Fowlkes, J.; Rouleau, C. M.; Geohegan, D. B.; Xiao, K. Twodimensional $\mathrm{GaSe} / \mathrm{MoSe}_{2}$ misfit bilayer heterojunctions by van der Waals epitaxy. Sci. Adv. 2016, 2, No. e1501882.

(14) Dietl, T.; Ohno, H.; Matsukura, F.; Cibert, J.; Ferrand, D. Zener model description of ferromagnetism in zinc-blende magnetic semiconductors. Science 2000, 287, 1019-1022.

(15) Dietl, T.; Ohno, H. Dilute ferromagnetic semiconductors: Physics and spintronic structures. Rev. Mod. Phys. 2014, 86, 187.

(16) Zhang, M.; Huang, Z.; Wang, X.; Zhang, H.; Li, T.; Wu, Z.; Luo, Y.; Cao, W. Magnetic $\mathrm{MoS}_{2}$ pizzas and sandwiches with $\mathrm{Mn}_{n}(n=1-$ 4) cluster toppings and fillings: A first-principles investigation. Sci. Rep. 2016, 6, 19504.

(17) Lei, J.; Xu, M.-C.; Hu, S.-J. Transition metal decorated graphene-like zinc oxide mono-layer: A first-principles investigation. J. Appl. Phys. 2015, 118, 104302.

(18) Wu, Z.; Wang, Y.; Ye, Y.; Feng, J.; Zhang, M.; Luo, Y.; He, L.; Cao, W. First-principles study of monolayer $\mathrm{MoS}_{2}$ with deficient and excessive $\mathrm{Mo}_{n}$ and $\mathrm{S}_{n}(n=-3 \rightarrow 3)$ clusters on $5 \times 5$ supercells. Comput. Mater. Sci. 2016, 121, 124-130. 
(19) Topsakal, M.; Cahangirov, S.; Bekaroglu, E.; Ciraci, S. Firstprinciples study of zinc oxide honeycomb structures. Phys. Rev. B: Condens. Matter Mater. Phys. 2009, 80, 235119.

(20) Guo, N.; Lu, R.; Liu, S.; Ho, G. W.; Zhang, C. High catalytic activity of Au clusters supported on $\mathrm{ZnO}$ nanosheets. J. Phys. Chem. C 2014, 118, 21038-21041.

(21) Ma, D.; Wang, Q.; Li, T.; Tang, Z.; Yang, G.; He, C.; Lu, Z. CO catalytic oxidation on $\mathrm{Al}$-doped graphene-like $\mathrm{ZnO}$ monolayer sheets: A first-principles study. J. Mater. Chem. C 2015, 3, 9964-9972.

(22) He, A. L.; Wang, X. Q.; Wu, R. Q.; Lu, Y. H.; Feng, Y. P. Adsorption of an $\mathrm{Mn}$ atom on a $\mathrm{ZnO}$ sheet and nanotube: $\mathrm{A}$ density functional theory study. J. Phys.: Condens. Matter 2010, 22, 175501.

(23) Ta, H. Q.; Zhao, L.; Pohl, D.; Pang, J.; Trzebicka, B.; Rellinghaus, B.; Pribat, D.; Gemming, T.; Liu, Z.; Bachmatiuk, A.; Rümmeli, M. H. Graphene-Like ZnO: A Mini Review. Crystals 2016, 6,100 .

(24) Zhang, S.-L.; Wang, W.; Zhang, E.-H.; Xiao, W. Half-metallic ferromagnetism in transition-metal doped germanium nitride: A firstprinciples study. Phys. Lett. A 2010, 374, 3234-3237.

(25) Amin, B.; Arif, S.; Ahmad, I.; Maqbool, M.; Ahmad, R.; GoumriSaid, S.; Prisbrey, K. Cr-doped III-V nitrides: Potential candidates for spintronics. J. Electron. Mater. 2011, 40, 1428-1436.

(26) Feng, M.; Shao, B.; Cao, X.; Zuo, X. Dirac cones in transition metal doped boron nitride. J. Appl. Phys. 2015, 117, 17C118.

(27) Das, G. P.; Rao, B. K.; Jena, P. Ferromagnetism in Cr-doped GaN: A first-principles calculation. Phys. Rev. B: Condens. Matter Mater. Phys. 2004, 69, 214422.

(28) Bonanni, A. Ferromagnetic nitride-based semiconductors doped with transition metals and rare earths. Semicond. Sci. Technol. 2007, 22, R41.

(29) Schmidt, T. M.; Miwa, R. H.; Fazzio, A. Ferromagnetic coupling in a Co-doped graphenelike $\mathrm{ZnO}$ sheet. Phys. Rev. B: Condens. Matter Mater. Phys. 2010, 81, 195413.

(30) Anderson, P. W. New Approach to the Theory of Superexchange Interactions. Phys. Rev. 1959, 115, 2.

(31) Frandsen, B. A.; Brunelli, M.; Page, K.; Uemura, Y. J.; Staunton, J. B.; Billinge, S. J. L. Verification of Anderson Superexchange in $\mathrm{MnO}$ via Magnetic Pair Distribution Function Analysis and ab initio Theory. Phys. Rev. Lett. 2016, 116, 197204.

(32) de Groot, R. A.; Mueller, F. M.; Van Engen, P. G.; Buschow, K. H. J. New class of materials: Half-metallic ferromagnets. Phys. Rev. Lett. 1983, 50, 2024.

(33) Delley, B. An All-Electron Numerical Method for Solving the Local Density Functional for Polyatomic Molecules. J. Chem. Phys. 1990, 92, 508-517.

(34) Perdew, J. P.; Burke, K.; Ernzerhof, M. Generalized Gradient Approximation Made Simple. Phys. Rev. Lett. 1996, 77, 3865-3868. 